\title{
Returning to sexual stigma: post-trafficking lives
}

\author{
Diane Richardson and Nina Laurie
}

\begin{tabular}{|c|c|}
\hline Date of deposit & 04112019 \\
\hline Document version & Author's accepted manuscript \\
\hline Access rights & $\begin{array}{l}\text { Copyright (c) London School of Economics and Political Science } \\
2019 \text {. This work is made available online in accordance with the } \\
\text { publisher's policies. This is the author created, accepted version } \\
\text { manuscript following peer review and may differ slightly from the } \\
\text { final published version. }\end{array}$ \\
\hline $\begin{array}{l}\text { Citation for } \\
\text { published version }\end{array}$ & $\begin{array}{l}\text { Richardson, D., \& Laurie, N. D. (2019). Returning to sexual } \\
\text { stigma: post-trafficking lives. British Journal of Sociology, Early } \\
\text { View. }\end{array}$ \\
\hline $\begin{array}{l}\text { Link to published } \\
\text { version }\end{array}$ & https://doi.org/10.1111/1468-4446.12707 \\
\hline
\end{tabular}

Full metadata for this item is available in St Andrews Research

Repository at: https://research-repository.st-andrews.ac.uk/

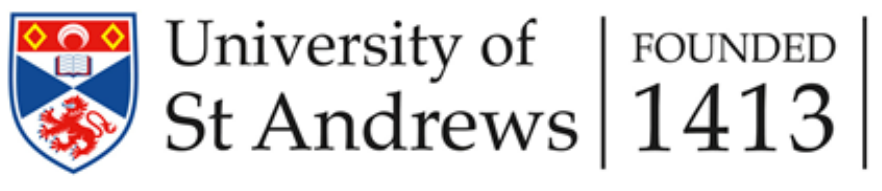




\title{
Returning to Sexual Stigma: Post-Trafficking Lives
}

\begin{abstract}
This article is concerned with returning to sexual stigma in two key respects. First, it prompts a return to the conceptual understanding of sexual stigma and makes an important contribution to critiques of the individualised frameworks that have dominated much of the literature on stigma to date, through a critical analysis of sexual stigma as a collective process at different scales and locations. Second, using empirical data from a qualitative study of post-trafficking experiences of women in Nepal as a case study to develop theoretical understandings of the production of stigma, it explores modalities of sexualised stigma encountered on return from trafficking situations. Within the trafficking literature there has been very little attention to what happens after trafficking. This article addresses this gap in focusing on lives post-trafficking and, in addition, contributes to the limited research on trafficking in Nepal.
\end{abstract}

\section{Key Words: Sexual Stigma, Post-Trafficking, Nepal, Stigma, Human Trafficking,} Gender.

\section{Introduction}

The concept of stigma has a long history and has been widely theorised. One of the most influential accounts is Goffman's $(1963,1969)$, in particular his classic work on the management of stigma and the consequences for people's lives. Goffman defined stigma as an 'attribute that is deeply discrediting' and that means an individual 'is thus reduced in our minds from a whole and usual person to a tainted, discounted one' (1990:12-13, our emphasis). He further distinguished between 'discredited' individuals, whose stigmatised 
aspect is known or visible, and 'discreditable' individuals, for whom the potential for stigmatization is unknown and not immediately recognizable. This has become the dominant approach in sociology and related disciplines, where stigma is understood in terms of individual attitudes and behaviour linked to negative cultural stereotypes and values. Adopting a symbolic interactionist approach, Goffman went on to qualify the notion of stigma as something an individual 'possesses' insisting that an attribute is neither credible nor discernible 'as a thing in itself' and that, as a consequence, 'it should be seen that a language of relationships not attributes is really needed' (Goffman 1990: 13).

Goffman's work prompted a raft of research on stigma, of which the vast majority have been social psychological studies. Despite Goffman's qualifications, much of this literature reaffirms the notion of stigma as a characteristic or attribute of persons, even if understood as socially constructed, which leads to the attribution of a 'spoiled' identity that is negatively valued. This article, through an examination of the experiences of women labelled 'trafficked', returns to the question of how stigma is inherently relational. Its focus is on stigmatization as a social process dependant on meaning-making through social interaction, demanding cultural understanding of visible 'markers' of stigma and of doubt or suspicion that place a person at risk of attribution of a stigmatized identity.

Researchers have examined the processes through which stigma occurs, and the impacts it can have on people's lives, in a wide variety of different circumstances, in particular in relation to health and disability. This includes work on the development of a concept of 'sexual stigma'. One of the first to address the relationship between sexuality and stigma was the British sociologist Ken Plummer in his book Sexual Stigma (1975). In this pioneering work, Plummer acknowledges a spectrum of sexual stigma associated with stereotypes of 
sexual 'deviance' including 'child molestation', 'prostitution' and 'unmarried motherhood', although his primary focus was on (male) 'homosexuality'. The work of Gayle Rubin (1984) has also been influential. Using the term 'erotic stigma', Rubin outlines how societies regulate sexuality in ways that construe some practices and relations as legitimate or 'good' (typically associated with marital, monogamous, reproductive sexuality that is coupled and occurs in private), and others as unacceptable or 'bad' that are subject to stigma (for example, sex that is non heterosexual, commercial, unmarried, casual, public, and involves the use of pornography).

Since then, a significant amount of research on the sexualisation of stigma has been conducted, much of it defining sexual stigma through analysis of 'the negative regard, inferior status, and relative powerlessness that society collectively accords to any nonheterosexual behaviour, identity, relationship, or community' (Herek 2007: 906-7). Other work includes studies of HIV/AIDs related stigma (Parker and Aggleton 2003) and research examining how normative assumptions about the appropriate expression of female sexuality, specifically through heterosexual marriage and motherhood, place women at risk of various forms of sexual stigma such as, for example, the stigmatization of young single mothers (Hancock 2004); stigma attached to 'sex work' and 'prostitution' (Campbell and O’Neill 2006; Weitzer 2017) and - the focus of this article- as a consequence of (sexual) trafficking (1) (Richardson et al. 2009; Poudel 2011; Russell 2013).

\section{Rethinking Stigma}

Though there is a well-established literature on stigma, critics of this body of work claim that despite its extensive use the concept of stigma is relatively under theorised and ill-defined (e.g. Link and Phelan, 2001: Scambler, 2009). They argue that studies have been largely 
descriptive, focused on specific stigma circumstances, with little theoretical development since Goffman, and that it is therefore important to rethink the construction of stigma and develop new theoretical frameworks to allow for more complex and nuanced analyses. In particular, critiques of stigma research post-Goffman have highlighted the limitations of individualistic frameworks that have dominated much of the literature and called for more sociologically informed approaches that examine the role of processes of stigmatisation in the reproduction of social difference and inequality (Parker and Aggleton 2003; Tyler and Slater 2018a). The emphasis in this more recent work is on recognising wider social, economic, cultural and political contexts in which stigma occurs and the role of social institutions and cultural understandings of value and worth in the production of stigma. In other words, there is an analytic shift away from a primary focus on stigma itself, its management and consequences, towards the (re)production of stigma where the focus is on identifying the key agents, institutions and discourses in stigmatisation processes.

Within this approach, power differences are central to the concept of stigma. For example, Link and Phelan (2001: 375) claim that although 'the role of power in stigma is frequently overlooked' it is the case that stigma 'is entirely dependent on social, economic, and political power - it takes power to stigmatize.' In this reframing of understandings of stigma, power differences are not only regarded as the determinants of stigma, but also as the consequence of stigmatization. Questions about why stigma is produced and for what purposes are often 'side-lined' in stigma research (Tyler and Slater 2018b). Here, in our analysis, stigma is conceptualised as a form of governance via the reproduction of culturally dominant/authoritative norms and social and economic structures that are productive of gendered and sexualised divisions. This represents a shift in scale, away from understanding stigma at the level of social interaction between individuals and groups, to a new focus on 
macro level factors that seeks to demonstrate how socio-economic structures and institutions reproduce stigma as an aspect of forms of local and nation-state power and governance.

A primary concern of recent sociological literature on stigma has been on the reproduction of race and class inequality; it has not, in the main, focused on sexuality. This is perhaps surprising given the provenance of the concept of sexual stigma. However, despite its sociological origins, studies of sexual stigma have been primarily located in the social psychological literature and health related research. The 'cultural turn' in theorising sexuality is also of relevance here, linked to the influence of queer studies where the dominant emphasis has been on cultural recognition rather than materiality and issues of socioeconomic inequality, reflecting a more general tendency to treat sexual and economic injustice as separate (Bedford and Jakobsen 2008).

The ways in which forms of sexual stigma are institutionalised are issues that are examined, in particular by feminist and queer scholars, in research on the regulatory processes whereby a certain sexual/social order is (re)produced. Rather than returning to the concept of sexual stigma, however, this literature emphasizes the notion of 'heteronormativity' which, in part, shares a similar focus to new work on stigma through its analysis of the production of inequalities via social institutions and cultural norms and practices that naturalize and privilege certain forms of (hetero)sexuality over other marginalised sexualities, characterised by social exclusion, discrimination and cultural devaluation (Warner 1993). This includes work that addresses the relationship between sexuality and the state (e.g. Canaday 2011; Tremblay et al. 2011), as well as scholarship on sexuality and citizenship, where the focus is on analysing the ways in which modes of citizenship are associated with exclusion from 
certain rights and forms of belonging on the grounds of sexuality (e.g. Bell and Binnie 2000; Richardson 2018).

These conceptual shifts away from a language of sexual stigma towards the use of terms such as heteronormativity and sexual citizenship reflect historical shifts in political struggles over sexual inequalities and the modes of action they inspired. Anti-stigma activism was a key aspect of lesbian and gay liberation movements of the late 1960s and 70s, which emphasized the political importance of 'coming out' and declaring oneself 'glad to be gay' and that 'the shame is over'. The impact of HIV/AIDS during the 1980s brought a new focus to antistigma campaigns in relation to sexual stigma. Since the 1990s, however, political activism around sexual inequality and discrimination has been dominated by claims for equal rights as 'ordinary citizens'; rights conferred as individuals rather than in terms of collective justice. Such demands have gained social and political currency enabling legislative change in many parts of the world that represents a shift towards formal legal equality and the normalization of (some) lesbians and gay men into mainstream culture. Associated with these social trends, is an analytical focus on homonormativity, which refers to the consequences of normalization and processes of social acceptance of non-heterosexuals (Duggan 2003). As a consequence, especially given that scholarship has been dominated by analysis of sexual 'minorities', sexual stigma has been rather left behind in sexuality studies.

This article prompts a return to the concept of sexual stigma. It draws both on contemporary work on stigma and scholarship in the field of sexual in/equalities and, through making these connections, extends attempts at reframing notions of the relations of stigma to the concept of sexual stigma and its effects. The focus of the discussion is on the sexualised (and gendered) stigma attached to women who have returned from trafficking situations, which has been clearly documented across 
cultures (e.g. Andrijasev 2010; Poudel 2011). In contrast to most stigma research, which examines discrete categories (Link and Phelan 2001), stigma associated with trafficking typically includes intersecting or co-stigmas, including being labelled as 'prostitutes', 'sex workers' and 'AIDS/HIV carriers' whether or not women have been trafficked into the sex sector or other forms of forced labour. As we have pointed out elsewhere (Richardson et al. 2009), many aspects of trafficking remain poorly understood and this includes analysis of trafficking related stigma that offers conceptual and theoretical development through a 'more nuanced understanding of how stigma is anticipated, embodied and articulated' (Russell 2013:83). This undertheorization of trafficking related stigma in part reflects a focus on policy analysis in much of the literature, and the fact that there is relatively little qualitative research that seeks to understand the process of trafficking and its effects from the perspective of women themselves.

This article contributes to addressing this gap in the literature through analysis of findings from empirical research in Nepal that examined how women returning from trafficking situations encounter, and deal with, stigma and marginalization. Most work on trafficking addresses its causes and characteristics, feeding into policy frameworks targeting the 'rescue' (2) of those experiencing diverse trafficking situations. Within this literature there has been very little attention until recently to what happens after trafficking (notable exceptions include Brennan 2014; Brennan and Plambech, 2018).

The study is therefore distinguished from previous work in focussing on post-trafficking. In the limited albeit growing body of research on post-trafficking that has been conducted, including some of our earlier work, the primary focus is on experiences upon return. However, post-trafficking can include a range of scenarios that are not exclusively about return. For instance, as we go on to discuss, state and non-state interventions may mitigate against women being able to return to their 
country and communities of origin. In extending conceptual understandings of post-trafficking, we also need to consider the relationship between the experience of trafficking and different points of 'returning'. In our analysis, we address this through an examination of the processes and practices associated with remaking lives, identities and livelihoods after leaving trafficking situations on returning 'home' and during the process of return.

At the same time as offering a clearer understanding of post-trafficking, of which sexual stigma is a key aspect, this article also contributes to the still limited literature on trafficking in Nepal, where relatively little empirical research has been conducted (see Hennink and Simkhada 2004; Poudel 2011; Laurie et al. 2015; Richardson et al. 2016). As a case study analysing sexual stigma in a nonWestern context, it also makes an important contribution to critiques of the conceptual limitations of western-centric constructions of stigma within the literature and, in so doing, to wider debates over decolonising sociological knowledge (see, for example, Connell 2007; Bhambra 2014; Gutierrez Rodriguez et al. 2016). Specifically, we argue that any critical reimagining of the concept of stigma needs to be accompanied by an examination of how stigma operates among social groups and in those parts of the world where -as is the case in Nepal- stigma is a more collective process involving family and kin, connected to issues of familial and community inclusion.

The remainder of the article is structured into three sections. First, we outline the research context and methodology of the study on which the empirical material drawn upon is based. Second, we identify key findings from the analysis of the narratives of women who had returned from trafficking situations that address the aims of the article. Finally, we reflect on the contributions our findings make to broader debates about stigma, sexual stigma and trafficking. 


\section{Research Context and Methodology}

The research was conducted at a time when Nepal was going through a period of significant change as part of transitions to democracy and the construction of a 'new' nation- state following the end of civil war in 2006. (For an analysis of these transitions more broadly see von Eiseniedel et al. 2012, for more specific discussion on the implications for women's rights see Richardson et al. 2016.) Despite some indication of new possibilities of doing gender and sexualities emerging 'post-conflict' that challenge traditional cultural expectations and social norms, Nepal remains a highly patriarchal society where there is 'social pressure to conform to heteronormative social conventions' and 'discrimination towards those who fail to conform' (Boyce and Cole 2013: 6). Nepal is a source country for cross border trafficking, in particular to India, and internally from rural to urban areas.

Women who are thought to have been trafficked, in particular sexually trafficked, are among the most stigmatised, excluded and vulnerable in Nepal. Other stigmatized groups include widows, single women, lesbians, sex workers, prostitutes and Badi women (Cox 2006). In addition to institutionalized discrimination against women and girls, Nepali society is also characterized by extreme poverty, a large rural population, and huge social diversity encompassing caste, ethnic, linguistic, economic, religious and regional differences (Gov Nepal 2011).

The study was carried out through research collaboration with Shakti Samuha, a leading antitrafficking NGO in Nepal which supports women who self-identify as trafficked and one of the first globally to be founded by post-trafficked women. Acknowledging that this is likely to have influenced the findings in certain respects, it is important to emphasise that it would be very difficult to carry out research of this nature, especially in this context, without access to a 'gatekeeper'. As a way of redressing the potential limitations imposed on the findings 
that might arise from this, we sought to include women in the sample who had differing levels of engagement with NGOs and other organizations concerned with trafficking issues. About a half of the women were recruited through their affiliation with anti-trafficking NGOs, a few through government shelters and about a third through snowballing techniques in order to access women without current, direct NGO contact.

Ethical concerns in research involving people who have been trafficked are widely recognised, in particular as a result of the vulnerabilities associated with being trafficked such as, for example, lack of social and legal status (in this case, including access to citizenship), financial precarity, fears about being identified by traffickers and health issues (see, for example, Seigel and de Wildt 2016). This study followed ethical protocols for carrying out research on human trafficking (WHO 20003) and was subject to ethical guidelines approval within our academic institution and the International Organization for Migration (IOM) Nepal Mission. In addition the methodology, including the research ethics procedures, was subject to review by the Economic and Social Research Council (ESRC) who funded the research.

Of crucial importance was following recommendations that researchers avoid potential harm, establish informed consent and ensure that anonymity and confidentiality be respected. For example, any information in the interview that could lead to a person being identified was removed and the transcripts were encrypted for further security in the sharing of data between the researchers who were based in the UK and Nepal during fieldwork. Other key ethical concerns were that those taking place felt emotionally safe and trusting of the researchers. The female researcher who carried out the non-stakeholder interviews was from Nepal, had long term involvement in trafficking issues and experience of conducting qualitative research 
in Nepal with women returning from trafficking situations. Also, she was well known to and trusted by the partner organisation Shakti Samuha and other anti-trafficking networks.

In depth semi structured interviews were conducted with 46 women ranging from 17 to 44 years of age, who self-identified as trafficked. The sample included women who were from different caste/ ethnic groups and religious affiliation and were also differentiated according to age of being trafficked/returned, marital status, number of trafficking journeys, trafficking routes and timeframes of return, and access to citizenship. The majority of the women had been trafficked to India, with a few women trafficked internally in Nepal and six women elsewhere to the US, Kuwait, Lebanon and Saudi Arabia. Most of the women were sexually trafficked, over three quarters, with a few trafficked through a recruitment agency for domestic labour in the Middle East and one or two for the purpose of marriage.

The interviews examined women's own experiences of sexual stigma and were taped and transcribed in Nepali then translated into English. Although not the focus of analysis in this article, the methodology also involved analysis of policies on trafficking and citizenship, participant observation in policy forums and advocacy activities, and semi structured interviews with 23 stakeholders including donors, anti-trafficking activists, and key personnel in NGOs and government.

\section{Sexual Stigma as a Collective Process}

What does it mean to be labelled a 'trafficked woman'? The research demonstrated that to be called a 'trafficked woman' in this cultural context is to experience sexual stigma, hatred and social rejection. It is a label that is associated with shame, discrimination, loss of confidence, anxiety and fear of disclosure, loss of status, being devalued and considered 'spoiled'. It may 
mean being looked down on with 'disgust' and 'repulsion'.

These and other consequences of stigma shaped the extent to which the women were able to return to their communities of origin and resume their lives. Typically, as other studies have also demonstrated (Hennink and Simkhada 2004; Poudel 2011), the women had encountered rejection and ostracism from their families, as well as from friends and neighbours. This pattern of response needs to be understood in the context of the negative impact of sexualized stigma on family 'honour' and reputation that could also threaten family members with social exclusion from the wider community (Rankin 2003; Richardson et al. 2016). Honour cultures exist in many parts of the world and define value systems associated with particular cultural norms and traditions linked to gender and sexuality, which are key to individual and collective reputations. The stigmatization of individuals perceived to have transgressed normative boundaries is a way of managing the threat posed to communities and upholding normative expectations about gender and sexuality, which can result in the expulsion/isolation/ erasure of those within the population who are the source of shame and 'dishonour'. Understood in this way as a collective process, stigma reproduces a particular version of social reality and a gendered and sexualized social order. In the following section we consider this at local and nation-state scales.

\section{Sexual Stigma and the Nation/Local State}

Sexual trafficking was largely a taboo topic in Nepal until the mid 1990s, when it entered public discourse in a major way (Shakti 2008; Kaufman and Crawford 2011). In 1996 more than two hundred Nepali girls who had been trafficked were 'rescued' from Indian brothels as a result of large-scale police raids. The Nepali government refused to accept them initially. Many were held for up to six months in India in detention-like conditions where 
they were forced to undergo blood tests for HIV before being repatriated and were only allowed to leave Indian NGO shelters when Nepali NGOs were ready to take them back. Upon arrival in Nepal they were kept at the airport under intense media attention, which labeled them as prostitutes and a source of HIV (Shakti Samuha 2008:2). Some of the women who were returned to Nepal in 1996 participated in the post-trafficking study and spoke about the importance of this as a critical moment of national awareness, fuelled by the government and news media. As one of the founding members on the Executive Committee of Shakti Samuha commented:

In 1996 when we returned in Nepal the government gave [us] a tag 'container of HIV/AIDS'. The government and the society including the media portrayed us very negatively. They were spreading the news about us as - 'HIV carriers, container of AIDS' and they won't live long, they will transmit the disease in the society.

There is a growing literature on sexuality and the nation-state; in which the primary focus is on how historically sexuality has been key to establishing boundaries of nation-states and continues to assume a key role in nation-building discourses and politics, in terms both of advancing and resisting 'sexual democracy' (Parker et al. 2018). Analyses of the role of state power in reproducing sexual stigma has received relatively less attention, with some notable exceptions including governmental responses to HIV/AIDS and forms of stigmatized motherhood. That trafficked women have been actively excluded by the nation-state is a clear example of the role of state power, as well as the media, in the production and mediation of sexual stigma. As we have discussed in more detail elsewhere (Laurie et al. 2015), it was clear from our study that governance continues to operate through the legitimation and (re)production of sexual stigma connected to fears about the nation's health 
and security related concerns about border control linked to the open border with India (see also Shneiderman 2013).

It is important to situate this examination of the role of national border politics in the production of sexual stigma within global anti-trafficking discourses and frameworks existent at that time. The identification of the 'first' women returning from trafficked situations in Nepal as dangerous to the social fabric and health of the nation in 1996 chimes with growing international concern over the trafficking of women and children into the 'sex industry' around that time. This was linked, in part, to transnational feminist activism and women's movements facilitated by high-profile World Conferences on Women organized by the UN, in particular the 1995 conference Beijing (Correa et al. 2008), and state responses to criminalizing migration in a time of intensifying globalization. These movements encouraged the emergence of supranational responses to trafficking such as, for example, the first global legally binding instrument to set out an agreed definition of trafficking in persons: The United Nations 2000 (Optional) Protocol to Prevent, Suppress and Punish Trafficking in Persons, especially Women and Children (often referred to as the Palmero Protocol). Although further discussion is outwith the scope of this article, this raises important questions about analysis of the production of sexual stigma at global levels beyond a nation-centred analysis.

In addition to conceptualizing sexual stigma at transnational and national scales, there is also a need to consider how processes of stigmatization can operate at local community levels. The recent history of Nepal, which has been undergoing 'post-conflict' state restructuring since 2007, and the fact that it is a largely rural country, highlights the importance of examining the power of local governance practices and community norms. In Nepal, izzat 
(honour or respect) accrues to both individuals and households and serves to maintain and defend caste and gender hierarchies. In the case of women honour is linked to ideas of (sexual) 'purity', in the Hindu sense, associated with women's bodies. Crucially, women's sexuality can compromise men's honour and prestige, as well as 'the pedigree of an entire household or lineage' (Rankin 2003: 118). The dominant western-centric construction of sexuality as a private aspect of individual lives is challenged in this context, where it is key to the material and social relations of the community. Notions of 'contagion' and 'pollution' were also important in processes of social rejection and blame (see later discussion), both in terms of stereotypes of trafficked women as HIV/AIDS 'carriers' and fears of social 'contamination', in particular that trafficked women may 'spoil' other women (and men) in society.

These factors are all the more significant in Nepal, where many people live in small closeknit village communities regulated by Village Development Committees (VDCs). In these circumstances, women who are perceived as 'trafficked women' often have to leave 'home' and seek sustainable lives and livelihoods elsewhere. A few women had managed to conceal their experiences while living in their village, but for the majority this was not the case and for this reason many women had relocated, in most cases to the capital Kathmandu.

You can't hide it from your neighbours and people surrounding you providing that you are living in your own village. You can hide it just not opening up your mouth to anyone if living in places other than your village. (Bindu)

That said, it is important to recognize women's attempts to challenge the dominant discourse of izzat. Wilson (2015), for example, has detailed attempts to appropriate and transform the 
concept of izzat through an examination of gender and class struggles in Bihar in eastern India. In our study, there were also examples of resistance to the dominant male protectionist discourse of izzat. For example, a few women emphasized the importance of 'coming out' (3) and being open about a trafficking past as a necessary step towards ending stigma, stopping trafficking and bringing traffickers to justice. This was the view of Uma who commented:

If we stay hiding the trafficking of women will continue forever... If I had said I was not trafficked, I wouldn't have succeeded; the criminal wouldn't have been sentenced. I said yes I was trafficked because I wanted him to be punished and sentenced.

As we discussed in the introduction, much of the literature on stigma reinforces the notion of stigma as an attribute someone 'has'. The above quote, however, points towards the framing of stigma as a social construction dependent on (negative) cultural stereotypes and values that inform the process of stigmatization at two distinct levels. It is a process that is productive of the notion of 'trafficked woman' both at the level of an individual identity/ 'attribute' and as a collective category. Uma's stance on the wider social and legal significance of saying 'I was trafficked' also draws attention to the power dynamics operating in the process of stigmatization. In particular, it highlights the way that power differences are a consequence of stigmatization expressed as a form of self-governance in not 'coming out' and speaking about trafficking experiences or seeking legal redress.

Awareness of the consequences of being publicly recognized as a 'trafficked woman' led many of the women to recommend concealment and 'hiding' one's past. They employed a variety of 'hiding' strategies common to many other groups that are at risk of sexual stigma. 
These included erasure or omission of information that might raise suspicions; isolation and/or being highly selective in who they spoke to about their experiences; and 'passing' via the construction of fictional narratives. For example, one woman, Sita, who had been away from her village for two or three years, explained her absence in terms of joining the Maoist war that was ongoing at the time: 'I even pretended to have the sign of bullets on my body by showing the sign of chicken pox'.

Underlying most of the women's attempts to keep trafficking experiences hidden was maintaining a socially credible presentation of oneself as a usual person who is 'ordinary', defined in terms of gendered and sexualised norms for women of their caste, religion and ethnicity, and avoiding or minimizing the potential for doubt or suspicion about this. Markers that helped to remove or contest doubt that a woman had been trafficked and establish 'ordinariness' included: marital status, family support, trafficking routes and timeframe of return, and whether a woman returned with money helping her to 'pass' as a migrant worker (Brennan and Plambech 2018; Laurie and Richardson forthcoming.) What this demonstrates is that for many trafficked women managing sexual stigma is not so much about 'passing' as someone who they are not, but rather (re)constructing believable narratives around identities they once had, where markers of doubt around those narratives are highly significant.

\section{What Troubles Concealment?: Markers of Doubt}

Although some women had managed to conceal their past trafficking experiences, in one case for more than ten years, for most this was not the case. The women described varying levels of disclosure that had different kinds of significance for their lives. Empirically, in our study, potential stigmatisation through being outed as trafficked or as a consequence of raising 'doubts' around a woman's status was related to four key factors: family and community 
response, the 'rescue 'process, embodied aspects of stigma, and the role of marriage.

\section{Family and Community Response}

The extent to which the women could keep their past experiences hidden and avoid suspicion or 'discovery' depended on the discursive and material possibilities available to them.

Concealment is compromised where those who know about a woman's trafficking past 'out' her either directly, by making this public knowledge, or indirectly as a result of their actions towards her which arouse suspicion and initiate markers of doubt that can cause rumours to spread. Most of the women spoke of the significance of the presence of rumours and gossip in their village on their return. This was often linked to the extent to which they had encountered social rejection from their family and community, which was likely to draw attention to them and increased the chances of sexual stigma. As Jaya commented:

People were gossiping and commenting me saying this and that in the society. The time when I got affected [trafficked] my mother didn't eat the food cooked and touched by me... instead it was given to a cow. They listened to the society's backbiting and negative comments and based on that they excluded me from the house.

Similarly, if a woman or her family are denied the opportunity to participate in fundamental aspects of village life such as, for example, being excluded from religious rituals and community practices then this might raise questions about her. As Milan described:

They even blamed my father and commented him negatively; it was all because of me.

The society reproached us. The society discriminated against my

parents in ritual things such as worshipping. The society excluded him in the meetings. 
My father is leader like person. ... Earlier he used participate in all the meetings held in the villages. My father was excluded from all those activities.

The phrase 'even blamed' points to how our analysis contributes to a key aspect of rethinking stigma, moving beyond signaling shame to analysis of the relationship between cultural norms of shame and blame (Scambler 2009, Tyler and Slater 2018a). Sociological work on sexuality has also highlighted how the stigmatization of both individuals and social groups as sexually 'irresponsible' can lead to associated blame such as, for example, in the case of 'teenage pregnancy', single motherhood and sexually transmitted diseases. This was also a key finding in our study. Trafficking experiences are commonly framed through the (contested) language of 'victims', which might suggest being seen as deserving of care and support. And yet, despite the fact that the women defined trafficking as being forced against one's will and had typically been tricked or coerced, if it became known on their return they had been trafficked they were not only shamed as 'spoiled' women, they were also held to blame for the circumstances they found themselves in for doing 'bad work' (prostitution/sex work) and bringing HIV/AIDS into the country. In talking about the $c o$-stigmas that trafficked women may encounter Saraswati, for instance, illustrates this point commenting that: HIV positive women are facing more [stigma] because they are blamed both for trafficking and spreading HIV.

As discussed earlier, the perceived threat that women labelled as trafficked posed to family honour and community relations, as well as to certain places and spaces, were other aspects of the attribution of blame associated with contravening boundaries of moral behavior linked to gendered and sexual norms. In addition, the women also highlighted the use of blame by the media and state authorities. The governmental exercise of abjection and blame, 
which we discussed earlier, is an important aspect of the development of new understandings of stigma at different scales and locations. In our case, the focus is on how political use of stigma supports policies that represent not only a concern with national border making in relation to state interests in maintaining health and security, but also in terms of reinforcing borders governing cultural norms defining 'good' and 'bad' gendered/ sexualized citizens and relations (Laurie et al. 2015; Richardson 2018; see also Joshi 2001).

Such negotiations are likely to be mediated to a large extent through the power of place-based social/kinship networks including local officials and members of VDCs. Here we need to consider the relative power of those who are stigmatized vis a vis stigmatizers. Who has the authority to label a woman as trafficked, or to raise doubts over her status, and this carry weight? To what extent does a woman have the power to refute those who reject and label her? In this study, at the time they returned from trafficking situations, most of the women were young, unmarried, poor and homeless, living in a patriarchal culture which shapes women and girl's status in ways that render them unequal in many respects to men who occupy positions of power within families and village communities. In the case of women labelled as trafficked, their ability to leverage these networks is likely to be further compromised through processes of stigmatization and associated 'dishonour'.

\section{The 'Rescue' Process}

In one or two cases becoming known as 'trafficked' was the result of seeking prosecution of the traffickers, while for other women it was because they had been 'outed' by their family or by an anti-trafficking NGOs via aspects of the 'rescue' process. Although some women may 'escape' through their own independent means, studies suggest that most women leave trafficking situations through being 'rescued' by state actors including the police, border 
guards and social/health workers with the support of NGOs and anti-trafficking organisations (Hennink and Simkhada 2004; Brennan and Plambech 2018). This was a common experience in our research, which demonstrated how the 'rescue' process and the policy and practice of anti-trafficking NGOs can also contribute to a woman being identified as a 'trafficked woman.' Disclosure for about half of the women was through an NGO or the police directly contacting their family. There were also instances, as the following quotes illustrate, where NGOs had given personal details to the media or included identifying information in their own publications that meant a woman could be recognized. (4)

$$
\begin{aligned}
& \text { It [NGO] published mentioning my name and address ...So there was nothing to } \\
& \text { hide... My story was in TV news with my photo. (Bipana) }
\end{aligned}
$$

\author{
I stayed in an NGO. They did what I have asked them not to do. They just \\ changed my name, but clearly mentioned my father's and brothers' real names \\ as well as my home address and published it in books. (Jaya)
}

For some, it was a different kind of visibility that troubled concealment through the risk of being identified through association with an anti-trafficking NGO. Most of the women were either working at an anti-trafficking organisation, Shakti Samuha in particular, or residing in a government/NGO rehabilitation centre for trafficked women. (In part, this is likely to reflect the fact that recruitment was facilitated through our research partner Shakti Samuha.). This highlights how different aspects of sexual stigma can intersect in ways that may be mutually reinforcing; in this case lack of family support leading to unemployment and stigma associated with homelessness and the need to seek the support of anti-trafficking 
organizations. As Sapana explains living and working in an anti-trafficking hostel or organization can lead to stigma by association.

When I go to school, they ask about me and slowly there will be talk about Shakti Samuha. Shakti Samuha is helping me so they ask about it and I tell them that Shakti Samuha looks after trafficked women. So they ask are you a trafficked woman?... I replied that it doesn't mean all women are trafficked who are living in Shakti Samuha. And then they asked again, if so how come you are staying in that organization?

Thus, while shelters and hostels may offer important sources of support for women returning from trafficking situations, they may also be important in the production of stigma posttrafficking.

\section{Embodied Aspects of Stigma}

Of particular importance to the process of 'rescue', and the possibilities for remaking lives and returning to communities, are discourses of trafficking, including stereotypes that provide 'cues' for potential recognition and attribution of the label 'trafficked woman'. As we noted in the introduction, and as Russell (2013) has also argued, the embodied aspects of stigma in relation to trafficking are often neglected. The women in our study clearly articulated an embodied narrative of trafficking. Of relevance to the discussion here, was reference to the fact that a woman's embodied presence may be cause for doubt where there is a certain degree of congruence with stereotypic assumptions about the ethnicity of trafficked women and routes of trafficking. 
To the extent that stigmatization processes are based on physical appearance, this might appear to reaffirm the notion of stigma as a characteristic or attribute. However, as we argue, it is not simply a case of reading what is already 'written on the body'. That aspects of physical appearance are rendered 'recognizable' as a 'mark' of trafficking is a social process of interpretation mediated especially by authoritative meaning makers who have the power to name. Elsewhere we have written about how ethnic stereotypes can influence being 'recognized' as a 'trafficked woman' by border guards and anti- trafficking organisations at the border crossing between Nepal and India (Laurie et al. 2015); a process that both draws upon and reproduces cultural norms around trafficking.

In addition to ethnic appearance, the use of particular kinds of make-up or wearing types of sari and jewellery, for instance, can mark women's bodies as 'out of place' in contrast to those who more closely approximate Nepali cultural norms of embodiment and are able to 'hide' more easily. Geographies of stigma associated with routes of trafficking are highly significant, as well as geographies of concealment and 'passing'. In particular, association with India and 'Indian-ness' can lead to the assumption not only that a woman has been trafficked but also that she has been sexually trafficked (Authors, forthcoming).

The majority of the women in the study had been trafficked to India and for some of these, especially those who had been trafficked at a very young age, their manner of dress and speaking meant they were highly visible on returning to Nepal. Maya, for example, stood out because of the jewellery she wore: 'My own aunt had once said bad things - women wearing finger ring on their feet fingers are prostitutes'. Sushila also commented on of how some women stood out because of the way they dressed and spoke when they came back from India, in contrast to women who had been trafficked within Nepal. 
The India returned women are easily recognized as trafficked ones as they look thin, maybe with some health issues; some even speak Hindi, wear like Indian woman, make up, etc. And society finds it difficult to distinguish the women sold inside country as trafficked because these women hardly change their outlook, dress and language. Only if they are told about destination do people know about it.

This latter quote suggests that assumptions about normative healthy bodies are also important, where illness might imply having HIV. It was also clear from the findings that there were embodied aspects to recognition as a 'trafficked woman' associated with the emotional after effects of trafficking experiences and social rejection such as, for instance, fearfulness, anxiety and a loss of confidence.

Clearly some markers of doubt associated with aspects of physical appearance can be more easily managed than others such as removing jewelry or changing the clothes one wears. Other aspects of embodiment that may signify bodies as 'trafficked', such as the ill body or the language one speaks, are more enduring making it very difficult to 'pass' or 'hide' and increase the likelihood of sexual stigma.

\section{Marriage}

Apart from the gendered power dynamics inherent in everyday interactions, as discussed earlier in relation to 'honour' economies, it is important to consider sexual stigma at cultural and structural levels in other respects. Cultural norms of gender and sexuality, marriage in particular, are important in (re)constituting a 'normal' identity as a usual person; an 'ordinary' woman. A person who is seen to be out with these norms is likely to encounter 
questions and suspicion. In Nepal's highly heteronormative society a woman who remains unmarried faces significant challenges to her status. As Tara explained, people will ask “"What type of girl is she?”, it is a sort of suspicion regarding her character'. This suggests that for post-trafficked women marriage becomes even more important since the informal recognition of belonging is often not forthcoming from their own communities and villages.

As discussed above in relation to embodiment, some signs that might be associated with having been trafficked are easier to hide than others; whether one is married or not is usually a matter of public knowledge. Relatively few of the women in our study were married before they were trafficked, in part reflecting their age, although after their return from trafficking situations most had subsequently got married. At the time the interviews were conducted around a half of the participants were still married and about a third of the women were separated, divorced, widowed, with a few who had never married. Although one or two women did speak of love, marriage was overwhelming talked about in terms of being a key strategy for managing sexual stigma and gaining livelihoods. For some women it was also seen as a means by which a woman could access citizenship and the rights and services associated with having citizenship (Richardson et al. 2016).

The performative function that marriage can play in helping to manage suspicion and doubt, reducing the likelihood of being labelled as a 'trafficked woman' and consequently being subject to sexual stigma, is summed up in the words of Jalna who saw marriage as a very powerful means of concealment.

If the woman is married, the society won't even think she was trafficked (laugh). The society looks at you differently if you are married. If a woman gets married 
right after her return, no one would know that she was trafficked.

For the majority of the women in the study whose family and community were aware they had been trafficked marriage was not so much a 'hiding' strategy, but rather a key way for managing sexual stigma and discrimination associated with the disclosure of a trafficking past. It is worth noting, however, that some of the women did not regard the situation as this clean cut. For instance, Sita commented that although marriage may lessen the public expression of stigma, it may persist in a more privatized form. As she described in her own words: 'They may perhaps gossip against us, but they don't at least stigmatize us directly in front'.

\section{Conclusion}

In this paper, we have examined modalities of sexual stigma encountered by women returning from trafficking situations. Drawing on an understudied aspect of research on trafficking, analysis of women's own experiences post-trafficking, this case study emphasises how 'markers of doubt' can place women at risk of being stigmatized as trafficked and how family and community response, the 'rescue ' process, the role of marriage, and embodied geographies of stigma connected to national border politics, are highly significant in this context. This analytical emphasis on familial relationships and anti-trafficking and NGO community relations demonstrates the importance of the social context into which women leaving trafficking situations return. It highlights how the marking of post-trafficked lives as subject to sexual stigma can inform decisions to leave 'home', due to family and community pressures and the role of local governance within villages, or in some cases not to return 'home' at all. 
The support services and spaces that are available for women post-trafficking, such as government hostels and anti-trafficking NGO 'shelters', may also be associated with sexual stigma that may influence decisions about seeking support post-trafficking. This is also a significant contribution to the literature, as few detailed studies have addressed the question of why someone who has been trafficked may seek to thwart rescue attempts and actively decline assistance and support (Soderlund 2005; Brennan and Plambech 2018). A clear understanding of the nature of and reasons for the various modalities of sexual stigma that women encounter in the process of returning from trafficking situations is therefore necessary in considering how women who are labelled 'trafficked' can be supported in ways that do not make them more likely to be stigmatized, with consequential effects.

The empirical research we have presented is important for rethinking the possibilities of posttrafficking lives. It also contributes to the growing body of scholarship within sociology that adopts post and de-colonial approaches to transform the discipline through de-centering western-centric constructions of knowledge and theoretical concepts. In this case, the focus is on rethinking the concept of stigma, sexual stigma specifically, offering a social, cultural and political analysis of the means by which stigma is mediated through the role of nation-state and local governance; gendered social structures and power relationships; and NGO discourses and practices. In doing so, the article extends theoretical understandings of sexual stigma, developing a critical response to understanding stigma through an individualised lens that underscores the importance of paying attention to the social and political processes which produce stigma. Understood in this way, we emphasize how, in post-trafficking contexts, sexual stigma (re)produces a particular (harmful) version of social reality and an (unequal) gendered and sexualized social order. 


\section{Footnotes}

1. The term (sexual) trafficking is adopted for two reasons. First, to indicate how stigma is attached both to trafficking and sexual trafficking. As one woman commented: 'The term 'trafficked' itself doesn't sound good. The term itself bears shocking connotation'. Second, to highlight how constructions of trafficking are sexualized, where there is a blurring of the label trafficking and sexual trafficking.

2. The reason for the use of quotation marks around 'rescue' is to highlight the problematic nature of this term, in particular that the process of 'rescue' may increase vulnerability and lead to the production of stigma post-trafficking. It also pertains to wider critiques of the 'rescue industry' (see, for example, Soderlund, 2005).

3. 'Coming out' has a different meaning in this context. Typically, 'coming out' is used to describe the process of voluntary disclosure of the 'truth' about who you feel yourself to be and want to be socially recognised as, primarily in relation to nonnormative sexual and gender identities. In the case of women returning from trafficking situations, coming out as trafficked may be about authenticity and recognition at one level, but not in the same sense of validating an identity they positively sought or wanted to be known as. This links back to the point we made in the introductory section on how analyses of heteronormativity, although important, have framed the language for analysis of experiences such as 'passing' and 'coming out' in ways that may limit understanding.

4. As the only anti-trafficking NGO to be named in this article, it should be noted that these quotations do not refer to Shakti Samuha. 


\section{Acknowledgements}

We would like to express our thanks to Shakti Samuha and all the returnee trafficked women who shared their stories with us, and to Dr Meena Poudel and Dr Janet Townsend who worked on the project with us. We would also like to thank the anonymous reviewers for providing useful and constructive comments and suggestions, which helped to improve the argument. The research for this paper was funded by the Economic and Social Research Council - ESRC Res-062-23-1490: 'Post Trafficking in Nepal: Sexuality and Citizenship in Livelihood Strategies'. Diane Richardson would also like to acknowledge the support provided by the award of a Leverhulme Trust Major Research Fellowship, 'Transforming Citizenship: Sexuality, Gender and Citizenship Struggles’ [award MRF-2012-106].

\section{References}

Bedford, K. and Jakobsen, J. 2008 'Toward a Vision of Sexual and Economic Justice', New Feminist Solutions 4. www.barnard.edu/bcrw.

Bell, D. and Binnie, J. 2000 The Sexual Citizen: Queer Politics and Beyond, Cambridge: Polity.

Bhambra, G. 2014 Connected Sociologies, London: Bloomsbury.

Boyce, P. and Coyle, D. 2013 Development, Discourse and Law: Transgender and SameSex Sexualities in Nepal, Brighton, UK: The Institute of Development Studies.

Brennan, D. 2014 Life Interrupted: Trafficking into Forced Labor in the United States, Durham, NC: Duke University Press. 
Brennan, D. and Plambech, S. 2018 'Editorial: Moving Forward-Life After Trafficking', Anti-Trafficking Review 10: 1-12.

Campbell, R. and O’Neill, M. (eds) 2006 Sex Work Now, London: Routledge.

Canaday, M. 2011 The Straight State: Sexuality and Citizenship in Twentieth-Century

America, Princeton, NJ: Princeton University Press.

Connell, R. 2007 Southern Theory: The Global Dynamics of Knowledge in Social Science, Cambridge: Polity Press.

Correa, S., Petchesky, R. and Parker, R. 2008 Sexuality, Health and Human Rights, London: Routledge.

Cox, T. 2006 The Badi of West Nepal: Prostitution as a Social Norm Among an Untouchable Caste, University of Michigan: Orchid Press.

Kaufman, M. R. and Crawford, M. 2011 'Sex Trafficking in Nepal: A Review of Intervention and Prevention Programs', Violence against Women 17 (5): 651-65.

Goffman, E. 1990 Stigma: Notes on the Management of Spoiled Identity, London: Penguin Books [first published in 1963] 
Goffman, E. 1969 The Presentation of Self in Everyday Life, London: Penguin Books.

Gutierrez Rodriguez, E. (acute accent over first e and i), Boatca, M. (curve inflection over last a), and Costa, S. (acute accent over e) (eds) 2016 Decolonizing European Sociology: Transdisciplinary Approaches, $2^{\text {nd }}$ edn. Abingdon: Routledge.

Hancock, A-M. 2004 The Public Identity of the Welfare Queen, New York, NY: New York University Press.

Hennink, M., and Simkhada, P. 2004 'Sex trafficking in Nepal: Context and Process', Asia Pacific Migration Journal 13(3): 305- 38.

Herek, G. M. 2007 ‘Confronting Sexual Stigma and Prejudice: Theory and Practice’, Journal of Social Issues 63 (4): 905-25.

Joshi, S. 2001 “"Cheli-Beti” Discourses of Trafficking and Constructions of Gender, Citizenship and Nation in Modern Nepal', Journal of South Asian Studies 24 (1): 157-75.

Laurie, N., Richardson, D., Poudel, M. and Townsend, J. 2015 'Post-trafficking Bordering Practices: Marking and Stretching Borders', Political Geography 48: 83-92.

Laurie, N. and Richardson, D. forthcoming 'Human Trafficking and Geographies of Stigma', 
Link, B.G. and Phelan, J.C. 2001 'Conceptualizing Stigma', Annual Review of Sociology 27: $368-85$

Parker, R., Russo, M., Sommer, D. and Yaeger, P. (eds) 2018 Nationalisms \& Sexualities, London: CRC Press, Taylor and Francis.

Parker, R. and Aggleton, P. 2003 'HIV and AIDS-related Stigma and Discrimination: A Conceptual Framework and Implications for Action', Social Science \& Medicine 57:13-24.

Plummer, K. 1975 Sexual Stigma: An Interactionist Account, London: Routledge \& Kegan Paul.

Poudel, M. 2011 Dealing with Hidden Issues: Social Rejection Experienced by Trafficked Women in Nepal, Saarbrucken, Germany: Lambert Academic Publishing.

Rankin, K. N. 2003 'Cultures of Economies: Gender and Socio-spatial Change in Nepal', Gender, Place and Culture 10 (2): 111-29.

Richardson, D. 2018 Sexuality and Citizenship, Cambridge: Polity.

Richardson, D., Poudel, M. and Laurie, N. 2009 'Sexual Trafficking in Nepal: Constituting Citizenship and Livelihoods', Gender, Place and Culture 16 (3): 259-78.

Richardson, D., Laurie, N., Poudel, M. and Townsend, J. 2016 'Women and Citizenship Post-Trafficking: The Case of Nepal', The Sociological Review 64 (2): 329-48. 
Rubin, G. 1984 'Thinking Sex: Notes for a Radical Theory of the Politics of Sexuality’, in C. S. Vance (ed.) Pleasure and Danger, London: Routledge \& Kegan Paul, pp. 267-319.

Russell, A. M. 2013 'Embodiment and Abjection: Trafficking for Sexual Exploitation', Body and Society 19 (1): 82-107.

Scambler, G. 2009 'Health-related Stigma', Sociology of Health and Illness 31 (3): 441-55.

Shakti Samuha 2008 Annual Report, Kathmandu: Shakti.

Shildrick, T. 2018 Poverty Propaganda: Exploring the Myths, Bristol: Policy Press.

Shneiderman, S. 2013 'Himalayan Border Citizens: Sovereignty and Mobility in the NepalTibetan Autonomous Region (TAR) of China Border Zone', Political Geography 35: 25-36.

Siegel, D. and de Wildt, R. (eds) 2016 Ethical Concerns in Research on Human Trafficking, London: Springer.

Soderlund, G. 2005 'Running from the Rescuers: New U.S. Crusades Against Sex Trafficking and the Rhetoric of Abolition', NWSA Journal 17 (3): 64-87.

Tremblay, M., Paternotte, D. and Johnson, C. (eds) 2011 The Lesbian and Gay Movement and the State: Comparative Insights into a Transformed Relationship, Farnham: Ashgate. 
Tyler, I. 2013 Revolting Subjects: Social Abjection and Resistance in Neoliberal Britain, London: Zed Books.

Tyler, I. and Slater, T. (eds) 2018 a The Sociology of Stigma, Sociological Review Monographs.

Tyler, I. and Slater, T. 2018b 'Rethinking the Sociology of Stigma', Sociological Review 66 (4): 721-44.

Von Einsiedel, S., Malone, D. M. and Pradhan, S. (eds) 2012 Nepal in Transition, Cambridge: Cambridge University Press.

Warner, M. 1993 'Introduction’ in M. Warner (ed.) Fear of a Queer Planet: Queer Politics and Social Theory, Minneapolis, MN: University of Minnesota Press.

Weitzer, R. 2018 'Resistance to Sex Work Stigma’, Sexualities 21 (5-6): 717-29.

WHO, Zimmerman, C. and Watts, C. 2003 WHO Ethical and Safety Information for Interviewing Trafficked Women, Geneva: WHO.

Wilson, K. 2015 'Towards a Radical Re-appropriation: Gender, Development and Neoliberal Feminism', Development and Change 46 (4): 803-32. 